\title{
Produção agronômica de uma coleção de acessos de Paspalum nicorae Parodi $^{1}$
}

\section{Emerson André Pereira ${ }^{2}$, Miguel Dall'Agnol ${ }^{3}$, Carlos Nabinger ${ }^{3}$, Kátia Graziela Costa Huber ${ }^{4}$, Daniel Portella Montardo ${ }^{5}$, Teresa Cristina Moraes Genro ${ }^{5}$}

\author{
1 Pesquisa parcialmente financiada pelo CNPq. \\ 2 Programa de Pós-Graduação em Zootecnia/UFRGS, Departamento de Plantas Forrageiras e Agrometeorologia, Caixa Postal 776 , \\ CEP: 91501-970, Porto Alegre, RS. Bolsista da CAPES. \\ 3 Departamento de Plantas Forrageiras e Agrometeorologia/UFRGS. Bolsista do CNPq. \\ ${ }^{4}$ Curso de graduação em Agronomia/UFRGS. \\ ${ }^{5}$ Embrapa Pecuária Sul, Caixa Postal 242, CEP: 96401-970, Bagé, RS.
}

RESUMO - Este estudo foi realizado para avaliar uma coleção de 53 acessos de Paspalum nicorae, estabelecidos em duas regiões fisiograficamente distintas durante dois anos, buscando caracterizar a produção e qualidade de forragem dos acessos para etapas subsequentes em programa de melhoramento de plantas forrageiras. Os acessos foram estabelecidos em linhas, num delineamento de blocos casualizados com três repetições, e as avaliações foram realizadas de outubro de 2007 a fevereiro de 2009 por meio de cortes. Houve variação da produção de forragem entre os acessos ao longo do tempo e entre os locais. A maioria dos acessos de $P$. nicorae apresentou elevado rendimento de forragem em comparação à testemunha (P. notatum cv. Pensacola) e alguns acessos apresentaram desempenho bem expressivo. Os percentuais de proteína bruta obtidos nos acessos da coleção foram semelhantes aos encontrados na testemunha. Os acessos 28B e 26A de $P$. nicorae são indicados para etapas subsequentes de um programa de melhoramento de plantas forrageiras.

Palavras-chave: espécie nativa, foragem, variabilidade

\section{Agronomic production of a collection of Paspalum nicorae Parodi access}

\begin{abstract}
This study was carried out to evaluate a collection of 53 accessions of Paspalum nicorae, introduced in two physiographically distinct regions over two years, with the objective of characterizing production and quality of forage of access for subsequent phases of a forage plant breeding program. The accessions were established in lines in randomized block design with three replications and the evaluations were performed from October 2007 to February 2009 by using cuts. There was variation of forage production among access over time and among sites. The majority of the accessions of $P$. nicorae presented high forage yield when compared with the control ( $P$. notatum cv. Pensacola) and some accessions presented very expressive performances. The percentages of crude protein obtained from accessions in the collection were similar to the ones found in the control access. The accessions 28B and 26A of P. nicorae are indicated for subsequent stages in a program of forage plant breeding.
\end{abstract}

Key Words: forage, native specie, variability

\section{Introdução}

O Bioma Pampa tem alta diversidade em sua composição botânica, com elevada quantidade de espécies forrageiras que fornecem forragem de qualidade aos herbívoros. No Rio Grande do Sul, as pastagens nativas são a base da alimentação pecuária e constituem a dieta de aproximadamente 74\% dos herbívoros (SEBRAE/FARSUL/ SENAR, 2005). Entretanto, essa imensa diversidade vem sendo substituída por outras culturas, como pastagens cultivadas exóticas ou, ainda, por florestas, também exóticas, e culturas para produção de grãos ou frutas, o que reduz a comunidade campestre natural.

As espécies do gênero Paspalum L. destacam-se pela maior resistência ao frio e pela produção e qualidade da forragem em comparação a outras gramíneas estivais nativas do Rio Grande do Sul (Dall’ Agnol et al., 2006). A importância das espécies desse gênero como pastagem cultivada tem sido confirmada por vários pesquisadores, principalmente por sua variabilidade, tanto intra como 
interespecífica (Schultze-Kraft, 1980; Batista \& Godoy, 2000). Atualmente, a cv. Pensacola é utilizada pelos produtores do Sul do Brasil por ser uma das poucas alternativas de espécies perenes de verão propagadas por sementes e pela facilidade de aquisição no mercado de sementes forrageiras. Entre as espécies do gênero, P. nicorae tem ampla adaptação a vários tipos de solos, especialmente os arenosos, e é tolerante a geadas e a secas moderadas (Pizarro, 2000). Assim, pesquisas têm sido realizadas para identificar espécies e acessos de plantas forrageiras mais bem adaptados às condições do ecossistema sul.

Este trabalho foi realizado para avaliar uma coleção de 53 genótipos de Paspalum nicorae estabelecidos em duas regiões do Rio Grande do Sul durante dois anos, buscando a produção e qualidade de forragem dos acessos para seleção daqueles com maior desempenho para futuras pesquisas. Os materiais selecionados serão incorporados em etapas subsequentes do Programa de Caracterização de Germoplasma e Melhoramento de Plantas Forrageiras, pertencente ao Departamento de Plantas Forrageiras e Agrometeorologia da Faculdade de Agronomia da UFRGS.

\section{Material e Métodos}

Os experimentos foram realizados em duas regiões fisiográficas do estado do Rio Grande do Sul, na Campanha Gaúcha, no município de Bagé ( $31^{\circ} 25^{\prime} 00^{\prime \prime}$ S e 54 07' 00" W.) e na Depressão Central, em Eldorado do Sul $\left(30^{\circ} 05^{\prime} \mathrm{S}\right.$, $\left.51^{\circ} 39 " \mathrm{~W}\right)$. O período de avaliações foi de outubro de 2007 a fevereiro de 2009. No município de Bagé, o experimento foi instalado na área experimental da Embrapa Pecuária Sul, com clima mesotérmico subtropical, classe Cfa, segundo classificação de Köeppen (DNMET, 1992) e, no município de Eldorado do Sul, foi instalado na Estação Experimental Agronômica da Universidade Federal do Estado do Rio Grande do Sul, que apresenta clima Cfa, subtropical úmido com verão quente (Bergamaschi et al., 2003). Foram utilizadas plantas de uma coleção viva de acessos de $P$. nicorae, oriundos de uma coleta realizada em diversos locais no Rio Grande do Sul no ano de 2005. Desde então, esta coleção é mantida viva em vasos e foi utilizada para caracterização citogenética e morfológica da espécie (Reis et al., 2010).

No inverno de 2007, iniciou-se a produção de clones de cada acesso, que foram mantidos em sacos plásticos com substrato comercial em casa de vegetação.

Os experimentos foram conduzidos em linhas individuais, contendo em cada linha sete plantas do mesmo acesso, espaçadas $15 \mathrm{~cm}$ entre si e $40 \mathrm{~cm}$ entre linhas. O delineamento adotado foi o de blocos casualizados com três repetições. No dia 10 e 15 de outubro de 2007, ocorreram os transplantes dos acessos nos municípios de Bagé e Eldorado do Sul, respectivamente. Foram adicionados corretivos e fertilizantes, conforme recomendações da Rede Oficial de Laboratórios de Análise de Solos (2004) para gramíneas de estação quente. A adubação nitrogenada foi fracionada, de modo que $20 \mathrm{~kg} / \mathrm{ha}$ foram aplicados juntamente com os demais elementos no início do transplante e o restante da quantidade recomendada foi disponibilizado às plantas no início do perfilhamento e após cada corte. Em cada ano e local, foram aplicados $200 \mathrm{~kg}$ de nitrogênio, $100 \mathrm{~kg}$ de $\mathrm{P}_{2} \mathrm{O} 5$ e $80 \mathrm{~kg}$ de $\mathrm{K}_{2} \mathrm{O}$, na forma de ureia, superfosfato triplo e cloreto de potássio, respectivamente.

Em Bagé, a avaliação foi composta por 31 acessos de $P$. nicorae, um de $P$. guenoarum (Azulão), um de Chloris uliginosa L, e o acesso testemunha P. notatum cv. Pensacola. Em Eldorado do Sul, o experimento foi formado por 52 acessos de $P$. nicorae, dois de $P$. guenoarum (Azulão e Baio), um de C. uliginosa L. e mais a cv. Pensacola. A diferença no número de acessos deveu-se a problemas ocorridos durante a multiplicação das mudas.

As avaliações foram feitas por meio de cortes em $1 \mathrm{~m}$ linear em cada linha no momento em que a maior parte das plantas atingia a altura entre 0,20 a $0,30 \mathrm{~m}$. A altura do resíduo foi de $0,10 \mathrm{~m}$ a partir do solo para o $P$. guenoarum e 0,05 m para as demais espécies. Depois de cada corte, todas as amostras eram pesadas e as porções de dois blocos eram subamostradas com aproximadamente $100 \mathrm{~g} \mathrm{e}$ encaminhadas para separação morfológica (lamina foliar, colmo + inflorescência, material morto e outras espécies) e posteriormente secas a $65^{\circ} \mathrm{C}$ até atingirem peso constante.

A matéria seca total foi composta pela soma da produção de matéria seca de folhas e da matéria seca de colmos, enquanto a MS de folhas foi composta pela produção de matéria seca de lâminas foliares. Em Bagé, foram realizados dois cortes no primeiro período de avaliação nos dias 24/1/2008 e 11/3/2008 e três no segundo período, nos dias 11/11/2008, 17/12/2008 e 4/2/2009. Em Eldorado do Sul, foram realizados quatro cortes no primeiro período e três no segundo, nos dias 20/12/2007, 23/1/2008, 14/3/2008, 27/5/2008 e 31/10/2008,5/12/2008, 6/1/2009, respectivamente.

As análises de valor nutritivo foram realizadas com as amostras de dois blocos, formando uma amostra composta, realizada por meio da mistura de toda a amostra de cada um dos dois blocos. Foram utilizadas as lâminas foliares obtidas pelas separações morfológicas dos quatro cortes ocorridos no primeiro ano do experimento de Eldorado do Sul. As amostras foram encaminhas ao Laboratório de Nutrição Animal da Embrapa Pecuária Sul, em Bagé para obtenção dos teores de proteína bruta (PB), de acordo com o método proposto por AOAC (1984). 
A análise estatística foi realizada por meio das análises individuais de variância em cada local e da análise conjunta. Sempre quando significativas para o teste F, efetuou-se a comparação entre médias pelo teste de agrupamento ScottKnott a 5\% de probabilidade, por meio do programa GENES (Cruz, 2001) e o teste de Tukey a 5\% de significância por meio do pacote estatístico SAS (2001). Nas análises individuais em cada local optou-se em usar o esquema fatorial, considerando "acessos" e "anos" como fatores, utilizando-se os valores de todos os cortes realizados ao longo das avaliações. Na análise conjunta usou-se a produção média de cada local durante os dois anos avaliados e adotaram-se como fatores "acessos" e "locais".

\section{Resultados e Discussão}

No experimento conduzido na Região da Campanha, a análise de variância comprovou diferenças significativas entre os acessos e anos e efeito significativo também para a interação entre acessos $\times$ anos nas variáveis estudadas, o que indica variação dos acessos no decorrer dos dois anos analisados em Bagé (Tabela 1). No primeiro ano de avaliação, ocorreram dois cortes, o que resultou em produções de matéria seca total de 49,9 a 256 g.linha ${ }^{-1}$ para os acessos, com média de 119 g.linha ${ }^{-1}$. Foram formadas três classes: na primeira, foram classificados quatro acessos, na segunda, seis e, na terceira, 23. O grupo de destaque foi formado exclusivamente por acessos de $P$. nicorae (26A, 26D, 28E e 28C), os quais foram significativamente superiores aos demais no primeiro ano de avaliações. Reis et al. (2010), pesquisando a mesma coleção de $P$. nicorae, verificaram que esses materiais apresentam altura e comprimento de folhas superiores à média de todos os demais acessos dessa coleção, e isso pode ser indicativo de materiais superiores. Por outro lado, os acessos 17, 26F, 9 , 31B e 9A obtiveram desempenhos intermediários. Na classe

Tabela 1 - Produção de matéria seca total (g.linha ${ }^{-1}$ ) e porcentagem média de produção em relação ao cultivar Pensacola, em Bagé, Rio Grande do Sul, 2009

\begin{tabular}{|c|c|c|c|c|}
\hline \multirow[t]{2}{*}{ Acesso } & \multicolumn{2}{|c|}{ Ano } & \multirow[t]{2}{*}{ Total acumulado } & \multirow[t]{2}{*}{$\%$} \\
\hline & 2007-08 & 2008-09 & & \\
\hline P. nicorae $28 B$ & B $147,1 b$ & A $419,6 a$ & 566,7 & 244 \\
\hline P. nicorae $26 \mathrm{~A}$ & A $201,1 a$ & A $310,3 b$ & 511,4 & 220 \\
\hline P. nicorae $26 D$ & A $256,0 a$ & A $252,1 b$ & 508,1 & 219 \\
\hline P. nicorae $28 E$ & A $246,2 a$ & A $188,4 c$ & 434,5 & 187 \\
\hline P. nicorae 19 & A 133,0 c & A $296,9 b$ & 429,8 & 185 \\
\hline P. nicorae $27 B$ & B 82,7c & A $324,1 b$ & 406,8 & 175 \\
\hline P. nicorae $28 D$ & В $88,6 c$ & A $315,5 b$ & 404,1 & 174 \\
\hline P. nicorae $28 C$ & A $225,2 a$ & A $153,9 c$ & 379,1 & 163 \\
\hline P. nicorae $6 A$ & A $93,4 c$ & A $284,2 b$ & 377,6 & 163 \\
\hline P nicorae 9 & A $171,5 b$ & A $196,7 c$ & 368,2 & 159 \\
\hline P. nicorae $30 \mathrm{~A}$ & A $101,1 c$ & A $262,4 b$ & 363,5 & 157 \\
\hline P. nicorae 17 & A $158,3 b$ & A $198,3 c$ & 356,5 & 154 \\
\hline P. nicorae $26 F$ & A $158,2 b$ & A $187,8 \mathrm{c}$ & 345,9 & 149 \\
\hline P. nicorae $9 A$ & A $174,3 b$ & A $159,1 \mathrm{c}$ & 333,4 & 144 \\
\hline P. nicorae $6 B$ & A $112,1 c$ & A $220,4 c$ & 332,5 & 143 \\
\hline P. nicorae $12 \mathrm{~A}$ & A $121,4 c$ & A $209,5 c$ & 330,9 & 143 \\
\hline P. nicorae $31 B$ & A $147,7 b$ & A $179,4 c$ & 327,1 & 141 \\
\hline P. nicorae 4 & A $92,7 c$ & A $222,6 c$ & 315,3 & 136 \\
\hline P. nicorae $11 \mathrm{~A}$ & A $104,6 c$ & A $207,6 c$ & 312,2 & 135 \\
\hline P. guenoarum (Azulão) & B $63,3 c$ & A $234,7 c$ & 297,9 & 128 \\
\hline P. nicorae 18 & A $112,8 c$ & A $183,3 c$ & 296,1 & 128 \\
\hline P. nicorae $11 B$ & A $105,8 c$ & A $181,6 \mathrm{c}$ & 287,4 & 124 \\
\hline P. nicorae $13 B$ & A $110,9 c$ & A $163,3 c$ & 274,2 & 118 \\
\hline P. nicorae $4 \mathrm{~A}$ & A $87,3 c$ & A $179,2 \mathrm{c}$ & 266,4 & 115 \\
\hline P. nicorae $33 \mathrm{~A}$ & A $104,2 c$ & A $157,4 c$ & 261,6 & 113 \\
\hline P. nicorae $8 B$ & A $53,5 c$ & A $201,2 c$ & 254,6 & 110 \\
\hline P. nicorae $13 \mathrm{~A}$ & A $68,6 c$ & A $170,2 c$ & 238,8 & 103 \\
\hline P. notatum (cv. Pensacola) & A $68,3 c$ & A $163,7 \mathrm{c}$ & 232,0 & 100 \\
\hline P. nicorae 5 & A 49,9 c & A $181,6 \mathrm{c}$ & 231,5 & 100 \\
\hline P. nicorae $8 A$ & A $67,5 \mathrm{c}$ & A $162,5 c$ & 230,0 & 99 \\
\hline P. nicorae 3 & A $86,9 c$ & A $129,2 c$ & 216,1 & 93 \\
\hline P. nicorae $37 D$ & A $61,4 c$ & A $132,3 c$ & 193,6 & 83 \\
\hline Chloris uliginosa L. & A $99,7 c$ & A $81,2 c$ & 180,9 & 78 \\
\hline Média & 119,8 & 209,4 & - & - \\
\hline
\end{tabular}

Médias seguidas por letras minúsculas distintas na coluna diferem $(\mathrm{P}<0,05)$ entre si pelo teste Scott-Knott e médias seguidas por letras maiúscula na linha diferem $(\mathrm{P}<0,05)$ entre si pelo teste Tukey. 
com menor produção, está a testemunha (cv. Pensacola), os acessos Azulão e C. uliginosa L., além dos dezoito acessos de $P$. nicorae restantes.

No segundo ano, ocorreram três cortes e a variação continuou existindo entre os acessos, formando novamente três classes. Neste ano, o destaque ficou com o acesso 28B, que foi superior aos demais, aumentando significativamente sua produção no segundo ano, passando de 147,1g para 419,7 g.linha ${ }^{-1}$. O maior tamanho de folhas desse acesso pode ser uma das razões para sua maior produtividade, pois, de acordo com Reis et al. (2010), o acesso 28B apresentou altura média de $65,17 \mathrm{~cm}$ e comprimento de folhas de 29,2 cm, superiores às médias dos demais acessos, que foram de 50,18 cm e 26,91 cm, respectivamente. Outros acessos que tiveram aumento significativamente maior no segundo ano foram os acessos 27B e 28D, além do ecótipo azulão. Entretanto, houve alternância entre a posição dos acessos, como é o caso dos acessos 26A e 26D. Os outros dois que se destacaram no primeiro ano tiveram menor desempenho, encontrando-se na classe de menor rendimento (26D e 28C). Também nesta última classe, ficaram os cultivares Pensacola e C. uliginosa L., que formaram no total um grupo de 21 materiais de menor rendimento.

A produção média de todos os acessos no segundo ano foi superior em relação ao primeiro, passando de 119,8 a 209,4 g.linha ${ }^{-1}$, fato comum em plantas perenes que geralmente produzem menos no ano de estabelecimento (Steiner, 2005; Sawasato, 2007).

A variabilidade dos acessos para a característica MS de folhas (Tabela 2) foi maior que para produção de MS total. No primeiro ano, os acessos 26A, 26D e 28E foram superiores aos demais genótipos testados, enquanto, no segundo ano, os acessos 26 A e 28B foram superiores aos demais.

Tabela 2 - Produção de matéria seca de folhas (g.linha-1 $)$ e porcentagem média em relação à produção do cultivar Pensacola (P. notatum), em Bagé, Rio Grande do Sul, 2009

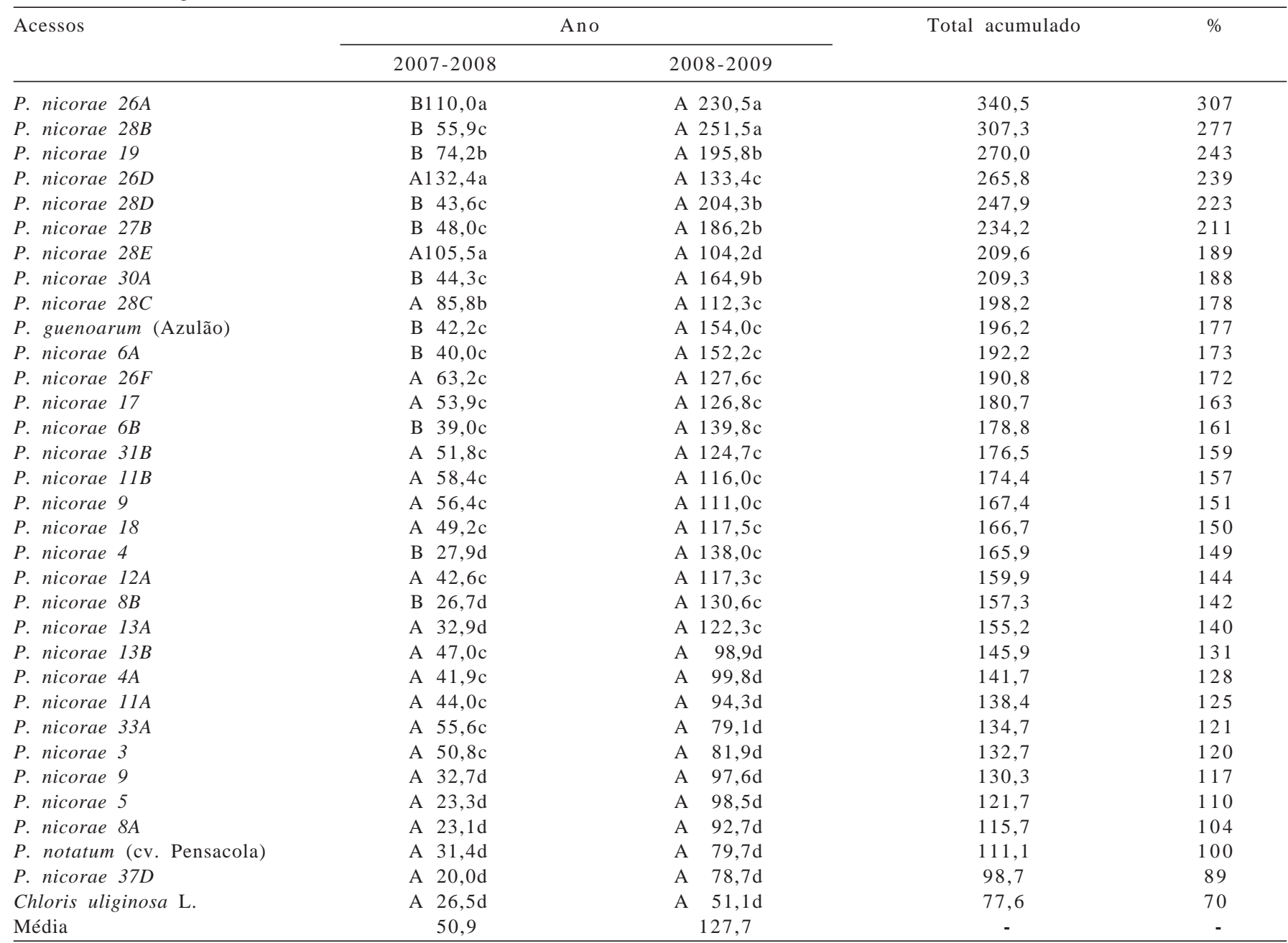

Médias seguidas por letras minúsculas distintas na coluna diferem $(\mathrm{P}<0,05)$ entre si pelo teste Scott-Knott e médias seguidas por letras maiúscula na linha diferem $(\mathrm{P}<0,05)$ entre si pelo teste Tukey. 
É importante destacar que os acessos 26 A, 26D e 28B também foram destaques na produção de MS total, o que indica que boa parte dessa produção é constituída de folhas. Nessa avaliação, o cv. Pensacola mais uma vez foi superado pela maior parte dos acessos analisados de $P$. nicorae.

No primeiro ano, 22 acessos de $P$. nicorae se diferenciaram do acesso testemunha, evidenciando superioridade de produção, enquanto, no segundo ano, 20 acessos foram superiores ao testemunha quanto à produção de matéria seca de folhas. Na média dos anos, a maioria dos acessos da coleção produziu mais folhas que o cultivar Pensacola; cinco acessos produziram mais que o dobro; e um acesso produziu cerca de 3 vezes mais. O ecótipo azulão produziu $77 \%$ a mais que o testemunha, valor superior aos relatados por Sawasato (2007), que obteve valores em torno de $40 \%$ para a média de dois anos de avaliação. Destacaram-se a variação de alguns acessos no decorrer dos anos e principalmente o aumento significativo da produção de folhas no segundo ano apresentado por alguns acessos (26A, 28B, 19, 28D, 27B, 30A, 6A, 6B, 4, 8B) e pelo ecótipo azulão. As folhas são a principal parte da planta, pelo seu maior valor nutritivo, com maiores valores de $\mathrm{PB}$, e pela digestibilidade (Alcântara, 1986) e também por ser responsável pela fotossíntese.

No experimento conduzido na Região da Depressão Central, a análise de variância revelou significância para os efeitos de acesso, ano e para interação acesso $\times$ ano, indicando presença de variabilidade dos genótipos no decorrer dos dois anos de avaliação em Eldorado do Sul (Tabela 3).

No primeiro ano, as quatro avaliações proporcionaram variação entre os genótipos de 38,2 a 218,8 g.linha ${ }^{-1}$ de MS total. Os genótipos que se destacaram pela maior produtividade foram: $P$. nicorae (28B, 26A, 18, 2A, 30B, 32A e 12A) e Baio. O cultivar Pensacola foi o que o teve menor produção, embora não tenha se diferenciado de alguns acessos de $P$. nicorae, que se mantiveram na média obtida por esses genótipos. De acordo com Reis et al. (2010), nos acessos 12A, 26A e 28B, a altura e o comprimento da folha ficaram acima da média da coleção de $P$. nicorae. Os acessos 30B e 12A apresentaram comprimento e largura de folhas maiores que a média na mesma avaliação. Além disso, o acesso 12A também apresentou o maior comprimento de colmo e foi um dos materiais com maior altura dentro da coleção estudada.

No segundo ano de avaliação, houve aumento na variação entre os genótipos. Dos oito genótipos mais produtivos no primeiro ano, apenas os acessos 28B e 26A mantiveram-se na classe superior no segundo ano, o que indica estabilidade de produção. Ainda pode ser destacado o desempenho do acesso 28C, que apresentou o maior valor produzido no período (262,9 g), fazendo parte da classe de melhor rendimento. $\mathrm{O}$ acesso 32A teve elevada capacidade de produção no primeiro ano, porém, no segundo ano, teve expressiva redução, mantendo-se no grupo de pior desempenho. Na comparação entre anos, apenas o acesso 28C teve aumento significativo para a produção de MS total no segundo ano. O ecótipo azulão apresentou baixo número de plantas durante todo o experimento, mas, mesmo assim, a diferença entre este e o cultivar Pensacola confirma os dados obtidos por Steiner (2005) e Sawasato (2007) em parcelas.

Novamente, o caractere MS de folha (Tabela 4) apresentou maior variabilidade do que o caractere MS total (Tabela 3), como observado nos resultados obtidos em Bagé. O caractere MS de folha é o mais importante e a maior variabilidade apresentada pelos diferentes acessos facilita a seleção.

No primeiro ano de avaliação, o ecótipo Baio foi o que apresentou maior produção de MS de folhas, entretanto essa produção teve decréscimo acentuado no segundo ano, quando apresentou desempenho estatisticamente inferior, embora tenha se mantido na classe mais produtiva também no segundo ano. No segundo ano, o cultivar Pensacola apresentou menor produção e não diferiu de alguns acessos de $P$. nicorae, cuja média de produção foi similar. Ressalta-se que, no primeiro ano, 31 acessos de $P$. nicorae diferiram do testemunha, evidenciando superioridade de produção, enquanto, no segundo ano, 44 acessos foram superiores ao testemunha. Na comparação entre anos, apenas o acesso 28C aumentou significativamente sua produção no segundo ano de avaliação.

Na análise estatística conjunta (Tabela 5), houve interação significativa entre acessos e locais. Houve grande variabilidade agronômica dos acessos entre os locais, ocorrendo a formação de quatro classes distintas ("a” a “d”). Em ambos os locais, as produções dos acessos 28B e $26 \mathrm{~A}$ de $P$. nicorae foram superiores às dos demais genótipos avaliados, juntamente com os acessos 26D em Bagé e 28C e 18 em Eldorado do Sul, incluídos na classe mais produtiva. O ecótipo azulão teve produção semelhante nos dois ambientes e foi classificado na classe intermediária. Já o cultivar Pensacola apresentou o menor rendimento, exceto se comparado ao C. uliginosa L. Esses resultados ratificam a importância da avaliação de genótipos nativos, que, apesar de não terem sofrido nenhum processo de melhoramento genético, indicam a possibilidade de obtenção de cultivares mais produtivos e adaptados. 
Tabela 3 - Produção de matéria seca total $\left(\right.$ g.linha $\left.{ }^{-1}\right)$ e porcentagem média em relação à produção da cv. Pensacola $(P$. notatum), em Eldorado do Sul, Rio Grande do Sul, 2009

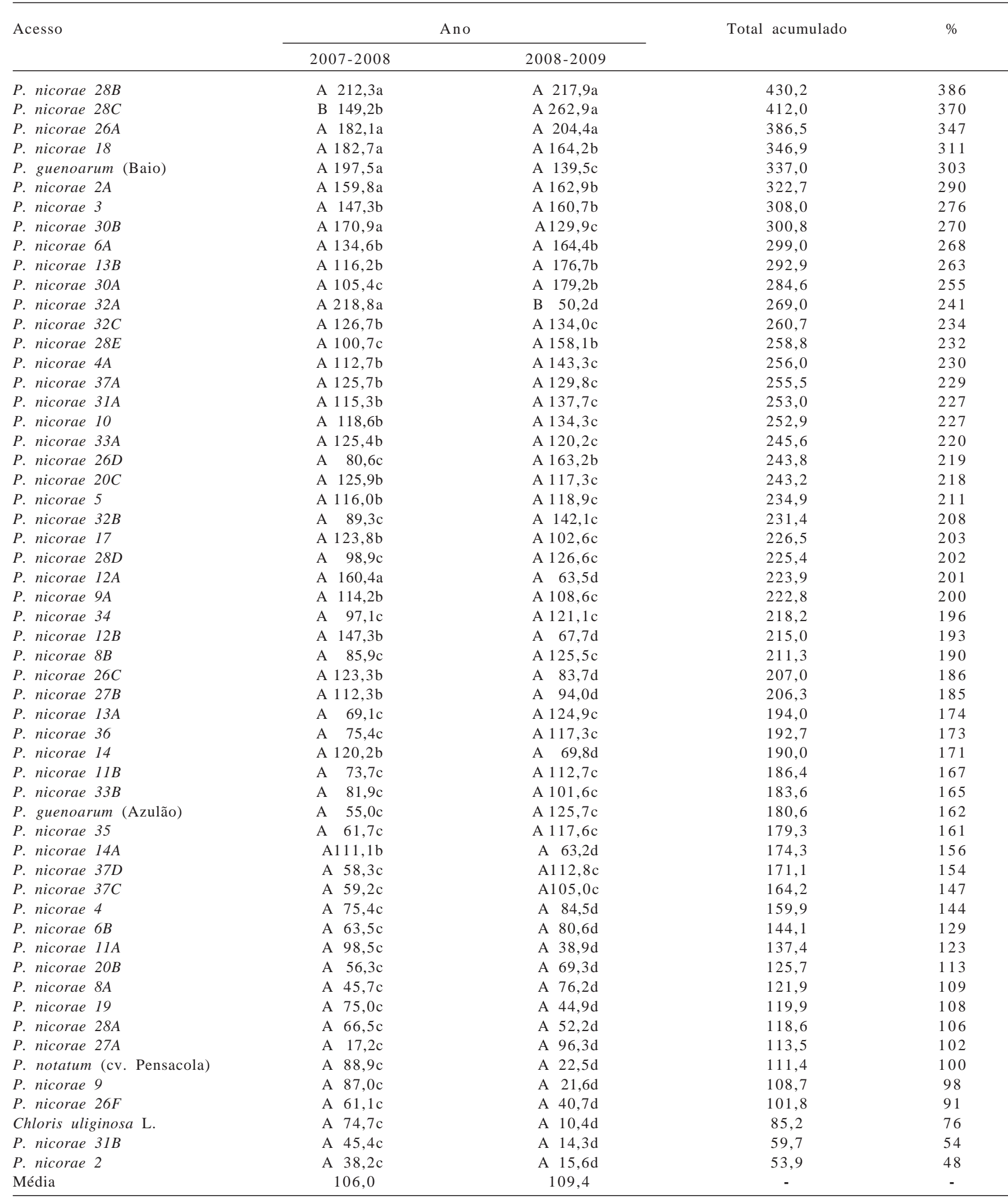


Tabela 4 - Produção de matéria seca de folhas (g.linha-1 $)$ e percentual médio em relação à produção do cultivar Pensacola (P. notatum) em Eldorado do Sul, Rio Grande do Sul, 2009

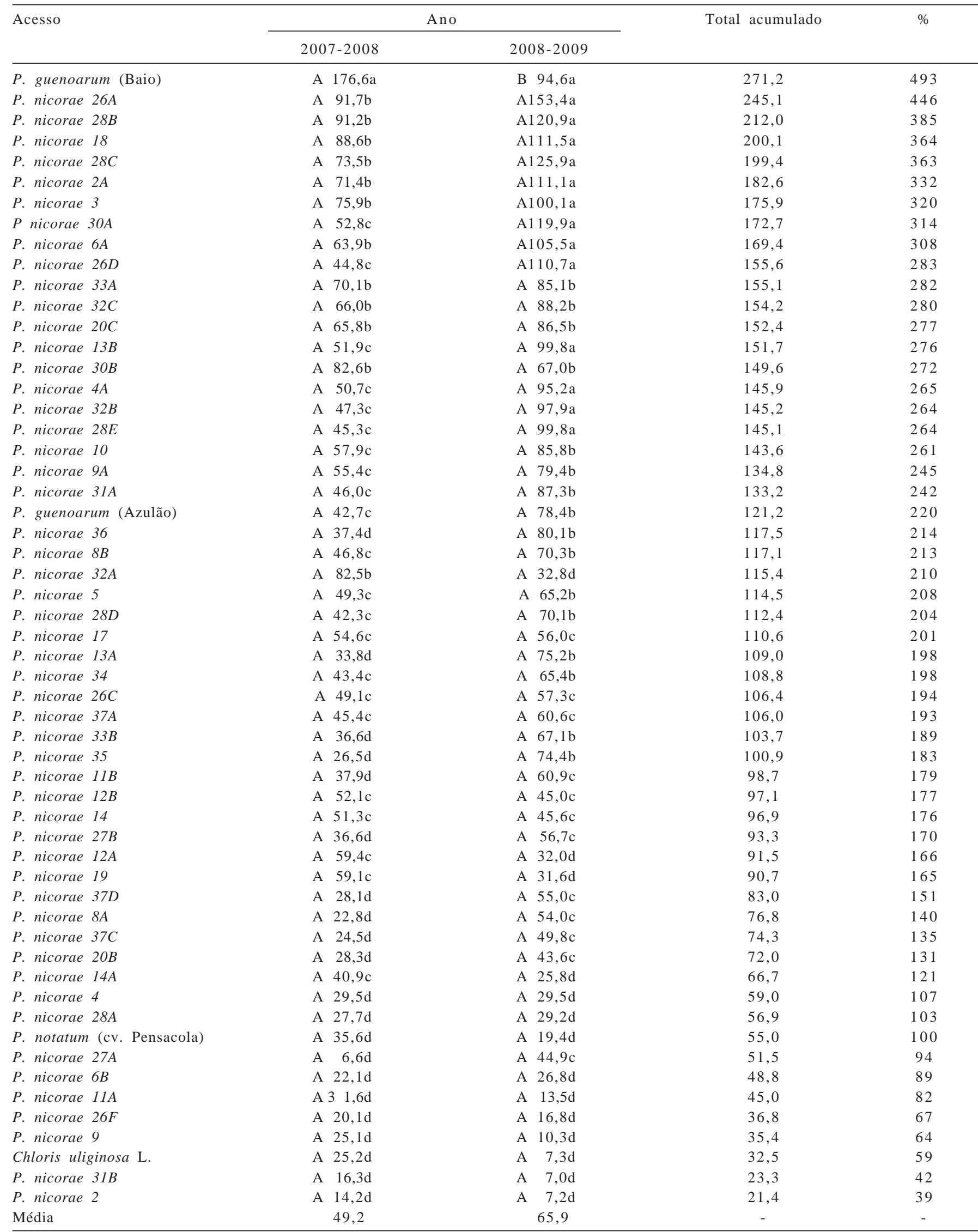

Médias seguidas de letras minúsculas distintas na coluna diferem $(\mathrm{P}<0,05)$ entre si pelo teste Scott-Knott e médias seguidas por letras maiúscula na linha diferem $(\mathrm{P}<0,05)$ entre si pelo teste Tukey. 
De maneira similar ao observado para a produção de MS total, novamente os genótipos 26A e 28B destacaram-se quanto à produção de MS de folhas (Tabela 6), tanto em Bagé como em Eldorado do Sul. Já os acessos 28C e 18 tiveram bom desempenho apenas em Eldorado do Sul. O azulão, o cultivar Pensacola e o C. uliginosa L. mantiveramse nas classes de menor produção de MS de folhas nos dois ambientes analisados.

A avaliação realizada em Bagé indicou maiores rendimentos em comparação àquela realizada em Eldorado do Sul, confirmando que esse ambiente foi mais favorável para o desenvolvimento dos genótipos. A persistência dos genótipos foi avaliada ao final do primeiro inverno (2007) e na segunda primavera (2008), por meio de notas visuais, e não houve diferença significativa entre os materiais; todos apresentaram boa persistência (dados não apresentados).
Embora não tenha sido realizada nenhuma análise relacionando os dados de produção de forragem com os respectivos locais de coleta, os cinco acessos que apresentaram os maiores valores numéricos de produção de folhas são originários de locais de coleta próximos (Alegrete, São Gabriel e Rosário do Sul). Além disso, quatro desses acessos foram coletados em apenas dois locais distintos (Alegrete e Rosário do Sul), e isso indica que, além de uma grande variabilidade entre locais, também houve grande diversidade dentro dos locais de coleta, apesar de tratar-se de uma espécie apomítica.

Os teores médios de proteína bruta das lâminas foliares (Tabela 7) nos primeiros quatro cortes realizados no verão de 2007 e outono de 2008 no experimento conduzido em Eldorado do Sul apresentaram variação nos quatro cortes, resultando em percentuais que variaram de 13,4 a $18,9 \%$, com média geral de $16,4 \%$. O cultivar

Tabela 5 - Produção média de matéria seca total (g.linha ${ }^{-1}$ ) e percentual médio da produção em relação ao cultivar Pensacola ( $P$. notatum) avaliados em dois ambientes, Rio Grande do Sul, 2009

\begin{tabular}{|c|c|c|c|c|}
\hline \multirow[t]{2}{*}{ Acesso } & \multicolumn{2}{|c|}{ Local } & \multirow[t]{2}{*}{ Média } & \multirow[t]{2}{*}{$\%$} \\
\hline & Bagé & Eldorado do Sul & & \\
\hline P. nicorae $28 B$ & $283,4 a$ & $215,1 \mathrm{a}$ & 249,2 & 290 \\
\hline P. nicorae $26 A$ & $255,7 a$ & $193,2 \mathrm{a}$ & 224,5 & 261 \\
\hline P. nicorae $28 \mathrm{C}$ & $189,5 b$ & $206,0 \mathrm{a}$ & 197,8 & 230 \\
\hline P. nicorae $26 D$ & $254,1 \mathrm{a}$ & $121,9 b$ & 188,0 & 219 \\
\hline P. nicorae $28 E$ & $217,3 b$ & $129,4 b$ & 173,3 & 202 \\
\hline P. nicorae $6 A$ & $188,8 b$ & $149,5 b$ & 169,1 & 197 \\
\hline P. nicorae $30 \mathrm{~A}$ & $181,7 \mathrm{~b}$ & $142,3 b$ & 162,0 & 189 \\
\hline P. nicorae 18 & $148,1 \mathrm{c}$ & $173,5 \mathrm{a}$ & 160,8 & 187 \\
\hline P. nicorae $28 D$ & $202,0 b$ & $112,7 c$ & 157,4 & 183 \\
\hline P. nicorae $27 B$ & $203,4 b$ & $103,2 \mathrm{c}$ & 153,3 & 179 \\
\hline P. nicorae 17 & $178,3 b$ & $113,2 \mathrm{c}$ & 145,8 & 170 \\
\hline P. nicorae $13 B$ & $137,1 \mathrm{c}$ & $146,4 b$ & 141,8 & 165 \\
\hline P. nicorae $9 A$ & $166,7 \mathrm{c}$ & $111,4 \mathrm{c}$ & 139,1 & 162 \\
\hline P. nicorae $12 \mathrm{~A}$ & $165,4 \mathrm{c}$ & $111,9 \mathrm{c}$ & 138,7 & 162 \\
\hline P. nicorae 19 & $214,9 b$ & 59,9d & 137,4 & 160 \\
\hline$P$ nicorae 3 & $108,0 \mathrm{~d}$ & $154,0 \mathrm{~b}$ & 131,0 & 153 \\
\hline P. nicorae $4 \mathrm{~A}$ & $133,2 d$ & $128,0 \mathrm{~b}$ & 130,6 & 152 \\
\hline P. nicorae $33 A$ & $130,8 d$ & $122,8 b$ & 126,8 & 148 \\
\hline P. guenoarum (Azulão) & $149,0 \mathrm{c}$ & $90,3 c$ & 119,6 & 139 \\
\hline P. nicorae 9 & $184,1 b$ & $54,3 d$ & 119,2 & 139 \\
\hline P. nicorae $6 B$ & $166,3 c$ & $72,1 \mathrm{~d}$ & 119,2 & 139 \\
\hline P. nicorae 4 & $157,6 \mathrm{c}$ & $80,0 \mathrm{c}$ & 118,8 & 138 \\
\hline P. nicorae $11 B$ & $143,7 \mathrm{c}$ & $93,2 c$ & 118,4 & 138 \\
\hline P. nicorae 5 & $115,8 d$ & $117,4 \mathrm{c}$ & 116,6 & 136 \\
\hline P. nicorae $8 B$ & $127,3 d$ & $105,7 \mathrm{c}$ & 116,5 & 136 \\
\hline P. nicorae $11 \mathrm{~A}$ & $156,1 \mathrm{c}$ & $68,7 d$ & 112,4 & 131 \\
\hline P. nicorae $26 F$ & $173,0 \mathrm{c}$ & $50,9 d$ & 111,9 & 130 \\
\hline P. nicorae $13 \mathrm{~A}$ & $119,4 d$ & $97,0 \mathrm{c}$ & 108,2 & 126 \\
\hline P. nicorae $31 B$ & $163,5 \mathrm{c}$ & $29,8 d$ & 96,7 & 113 \\
\hline P. nicorae $37 D$ & $96,8 d$ & $85,5 c$ & 91,2 & 106 \\
\hline P. nicorae $8 A$ & $115,0 \mathrm{~d}$ & $61,0 \mathrm{~d}$ & 88,0 & 102 \\
\hline P. notatum (cv. Pensacola) & $116,0 \mathrm{~d}$ & $55,7 d$ & 85,9 & 100 \\
\hline Chloris uliginosa L. & $90,5 d$ & $42,6 \mathrm{~d}$ & 66,5 & 77 \\
\hline Média & 164,6 & 109,1 & - & - \\
\hline
\end{tabular}

Médias seguidas da mesma letra nas colunas não diferem estatisticamente entre si a 5\% de probabilidade de erro pelo teste Scott Knott. 
Pensacola apresentou percentual médio de 16,6\%, enquanto, para os acessos Azulão, Baio e C. uliginosa L., os valores foram de 14,1; 14,4; e 13,4\%, respectivamente. Por outro lado, se utilizados somente os acessos de $P$. nicorae, o valor médio encontrado foi de $16,55 \%$ de PB para essa coleção. Esses valores corroboram relatos de Burson \& Bennet (1970) de que, quando há fertilização com nitrogênio, a qualidade de forragem de $P$. nicorae é comparável ao do cultivar Pensacola. Os valores encontrados para o P. guenoarum Azulão e Baio e para o cultivar Pensacola se assemelham aos descritos por Steiner (2005), de 14,3; 14,7 e 15,6\% de PB, respectivamente, em pesquisa com lâminas foliares dos acessos Baio, Azulão e com o cultivar Pensacola.
Os valores de PB obtidos em cada corte para os acessos de $P$. nicorae variaram de 15,4 a $17,8 \%$ nos quatro cortes. O primeiro corte apresentou a maior média, com valores entre 14,3 e 20,9\%, devido ao fato de que as plantas da maioria dos acessos se encontravam em estádio vegetativo no momento da avaliação. Houve pequeno decréscimo e pequena variação nos valores médios dos acessos a cada corte. Essa redução da qualidade está relacionada ao processo fisiológico pelo qual as plantas passam, que ocasiona diminuição na quantidade de proteínas e aumento da parede celular e do teor de lignina com o envelhecimento. Apesar disso, no quarto corte, o aumento médio pode ser atribuído à adubação nitrogenada realizada 14 dias antes dessa avaliação.

Tabela 6 - Produção média da matéria seca de folhas (g.linha ${ }^{-1}$ ) e percentual médio da produção em relação ao cultivar Pensacola (P. notatum) avaliados em dois ambientes, Rio Grande do Sul, 2009

\begin{tabular}{|c|c|c|c|c|}
\hline \multirow[t]{2}{*}{ Acesso } & \multicolumn{2}{|c|}{ Local } & \multirow[t]{2}{*}{ Média } & \multirow[t]{2}{*}{$\%$} \\
\hline & Bagé & Eldorado do Sul & & \\
\hline P. nicorae $26 A$ & $170,2 \mathrm{a}$ & $122,6 a$ & 146,4 & 353 \\
\hline P. nicorae $28 B$ & $153,7 a$ & $106,0 \mathrm{a}$ & 129,8 & 313 \\
\hline P. nicorae $26 D$ & $132,9 b$ & $77,8 b$ & 105,3 & 254 \\
\hline P. nicorae $28 \mathrm{C}$ & $99,1 \mathrm{c}$ & $99,7 a$ & 99,4 & 239 \\
\hline P. nicorae $30 \mathrm{~A}$ & $104,6 \mathrm{c}$ & $86,4 \mathrm{~b}$ & 95,5 & 230 \\
\hline P. nicorae 18 & $83,4 c$ & $100,1 \mathrm{a}$ & 91,7 & 221 \\
\hline P. nicorae $6 A$ & $96,1 \mathrm{c}$ & $84,7 b$ & 90,4 & 218 \\
\hline P. nicorae 19 & $135,0 \mathrm{~b}$ & $45,3 c$ & 90,2 & 217 \\
\hline P. nicorae $28 D$ & $124,0 \mathrm{~b}$ & $56,2 \mathrm{c}$ & 90,1 & 217 \\
\hline P. nicorae $28 E$ & $104,8 c$ & $72,6 b$ & 88,7 & 214 \\
\hline P. nicorae $27 B$ & $117,1 \mathrm{~b}$ & $46,7 c$ & 81,9 & 197 \\
\hline P. guenoarum (Azulão) & $98,1 \mathrm{c}$ & $60,6 c$ & 79,3 & 191 \\
\hline P. nicorae 3 & $66,4 \mathrm{~d}$ & $88,0 \mathrm{~b}$ & 77,2 & 186 \\
\hline P. nicorae $9 A$ & $83,7 c$ & $67,4 \mathrm{~b}$ & 75,5 & 182 \\
\hline P. nicorae $13 B$ & $72,9 \mathrm{~d}$ & $75,9 b$ & 74,4 & 179 \\
\hline P. nicorae 17 & $90,3 c$ & $55,3 c$ & 72,8 & 175 \\
\hline P. nicorae $33 \mathrm{~A}$ & $67,4 \mathrm{~d}$ & $77,6 b$ & 72,5 & 175 \\
\hline P. nicorae $4 A$ & $70,8 d$ & $72,9 b$ & 71,9 & 173 \\
\hline P. nicorae $8 B$ & $78,7 \mathrm{c}$ & $58,6 \mathrm{c}$ & 68,6 & 165 \\
\hline P. nicorae $11 B$ & $87,2 \mathrm{c}$ & $49,4 \mathrm{c}$ & 68,3 & 164 \\
\hline P. nicorae $13 \mathrm{~A}$ & $77,6 \mathrm{c}$ & $54,5 c$ & 66,1 & 159 \\
\hline P. nicorae $12 \mathrm{~A}$ & $79,9 c$ & $45,7 c$ & 62,8 & 151 \\
\hline P. nicorae 5 & $60,9 d$ & $57,3 c$ & 59,1 & 142 \\
\hline P. nicorae $26 F$ & $95,4 c$ & $18,4 d$ & 56,9 & 137 \\
\hline P. nicorae $6 B$ & $89,4 c$ & $24,4 \mathrm{~d}$ & 56,9 & 137 \\
\hline P. nicorae 4 & $82,9 c$ & $29,5 d$ & 56,2 & 135 \\
\hline P. nicorae $31 B$ & $88,2 c$ & $11,7 \mathrm{~d}$ & 50,0 & 120 \\
\hline P. nicorae $8 A$ & $57,9 \mathrm{~d}$ & $38,4 \mathrm{c}$ & 48,1 & 116 \\
\hline P. nicorae $11 \mathrm{~A}$ & $69,2 \mathrm{~d}$ & $22,5 d$ & 45,8 & 110 \\
\hline P. nicorae $37 D$ & $49,3 d$ & $41,5 c$ & 45,4 & 109 \\
\hline P. notatum (cv. Pensacola) & $55,5 d$ & $27,5 d$ & 41,5 & 100 \\
\hline P. nicorae 9 & $65,2 d$ & $17,7 d$ & 41,4 & 100 \\
\hline Chloris uliginosa L. & $38,8 \mathrm{~d}$ & $16,2 \mathrm{~d}$ & 27,5 & 66 \\
\hline Média & 89,3 & 57,8 & - & - \\
\hline
\end{tabular}

Médias seguidas da mesma nas colunas não diferem estatisticamente entre si a 5\% de probabilidade de erro pelo teste Scott Knott. 
Tabela 7 - Teor de proteína bruta (\%) nos quatro primeiros cortes da fração de lâminas foliares de P. nicorae, P. guenoarum (Azulão e Baio), P. notatum (cv. Pensacola) e de Chloris uliginosa L.em Eldorado do Sul - RS, UFRGS, 2009

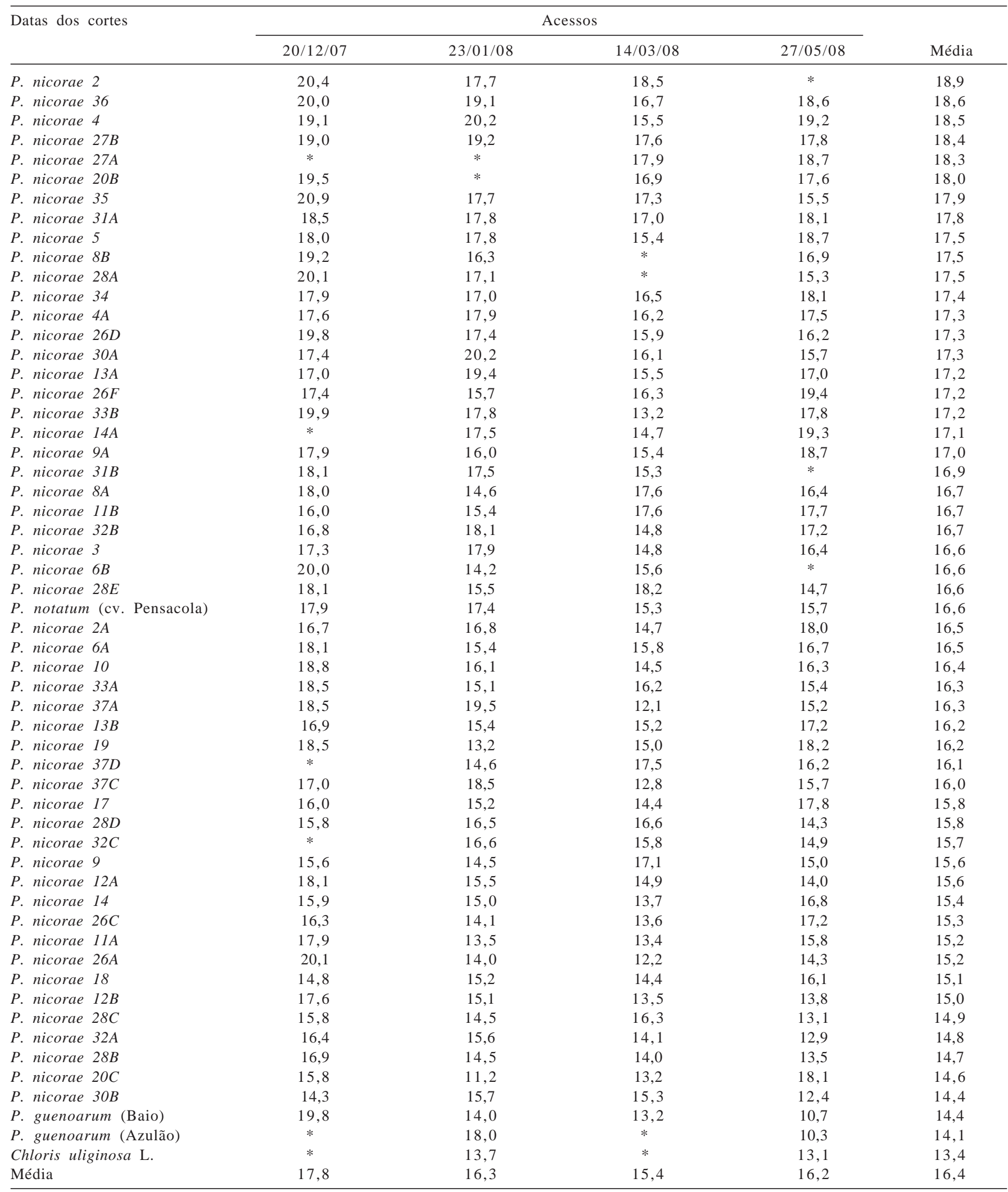

* Amostras não analisadas em função da pequena quantidade de material disponível. 


\section{Conclusões}

A coleção de $P$. nicorae tem desempenho superior ao do cultivar Pensacola, com alguns acessos apresentando produções expressivas de matéria seca total e de matéria seca de lâminas foliares. A produção de lâminas foliares permitiu maior discriminação entre os acessos. Por meio da análise conjunta, os acessos 28B, 26 A, 28C, 26D e 18, podem serem utilizados nas etapas subseqüentes de um programa de melhoramento de plantas forrageiras.

O ambiente da região da Campanha do Rio Grande do Sul (Bagé) proporciona maiores rendimentos em comparação à região da Depressão Central do Rio Grande do Sul (Eldorado do Sul). O teor de proteína bruta da maioria dos acessos é semelhante à cultivar Pensacola e superior ao dos acessos de $P$. guenoarum.

\section{Referências}

ALCÂNTRA, P.B. Origem das brachiarias e suas características morfológicas de interesse forrageiro: In: ENCONTRO PARA DISCUSSÃO SOBRE CAPINS DO GÊNERO BRACHIARIA, Nova Odessa, 1986. Resumos... Nova Odessa: Instituto de Zootecnia, 1986. p.1-14.

ASSOCIATION OF OFFICIAL ANALYTICAL CHEMISTS AOAC. Official methods of analysis. 14.ed. Washington, D.C.: 1984. 1141p.

BATISTA, L.R.; GODOY, R. Caracterização preliminar e seleção de germoplasma do gênero Paspalum para produção de forragem. Revista Brasileira em Zootecnia, v.29, p.23-32, 2000.

BERGAMASCHI, H.; GUADAGNIN, M.R.; CARDOSO, L.S. et al. Clima da Estação Experimental da UFRGS (e região de abrangência). Porto Alegre: Faculdade de Agronomia, Departamento de Plantas Forrageiras e Agrometeorologia, 2003. 78p.
BURSON, B.L.; BENNET, H.W. Cytology, method of reproduction, and fertility of brunswickgrass, Paspalum nicorae Parodi. Crop Science, v.10, p.184-187, 1970.

CRUZ, C.D. Programa GENES: aplicativo computacional em genética e estatística. Viçosa, MG: UFV, 2001. 648p.

DEPARTAMENTO NACIONAL DE METEOROLOGIA - DNMET. Normais climatológicas (1961-1990). Brasília: DNMET, 1992. 84p.

DALL' AGNOL, M.; STEINER, M.G.; BARÉA, K. et al. Perspectiva de lançamento de cultivares de espécies forrageiras nativas: o gênero Paspalum. In: SIMPÓSIO DE FORRAGEIRAS E PRODUÇÃO ANIMAL, ÊNFASE IMPORTÂNCIA E POTENCIAL PRODUTIVO DA PASTAGEM NATIVA, 2006 , Porto Alegre. Anais... Porto Alegre: Departamento de Plantas Forrageiras e Agrometeorologia UFRGS, 2006. p,149-162.

PIZARRO, E.A. Potencial forrajero del género Paspalum. Pasturas Tropicales, v.22, n.1, p.38-46, 2000.

REDE OFICIAL DE LABORATÓRIOS DE ANÁLISE DE SOLO E DE TECIDO VEGETAL ROLAS. Manual de adubação e calagem para os estados do Rio Grande do Sul e Santa Catarina. 10.ed. Porto Alegre: Sociedade Brasileira de Ciência do Solo, 2004. 400p.

REIS, C.A.O.; DALL'AGNOL, M.; NABINGER, C. et al. Morphological variation in Paspalum nicorae Parodi accessions, a promising forage. Scientia Agrícola, v.67, p.143-150, 2010

SAWASATO, J.T. Caracterização agronômica e molecular de Paspalum urvillei Steudel. 2007. 109f. Dissertação (Mestrado em Zootecnia) - Faculdade de Agronomia, Universidade Federal do Rio Grande do Sul, Porto Alegre.

SEBRAE/FARSUL/SENAR. Diagnóstico de sistemas de produção da bovinocultura de corte do Estado do Rio Grande do Sul. Relatório. Porto Alegre, 2005. 261p.

SCHULTZE-KRAFT, R. Recolecíon de plantas nativas con potencial forrajero. In: SIMPÓSIO SOBRE PLANTAS FORRAGEIRAS, 1979, Campo Grande. Anais... Brasília: EMBRAPA/CENARGEN/BID, 1980. p.61-72. (Documentos, 1).

STATISTICAL ANALYSES SYSTEM - SAS. SAS: STAT user's guide: statistics. Cary: State University Press; SAS Institute, 2001. (CR-ROM).

STEINER, M.G. Caracterização agronômica, molecular e morfológica de acessos de Paspalum notatum Flügge e Paspalum guenoarum Arech. 2005. 129f. Dissertação (Mestrado em Zootecnia) - Faculdade de Agronomia, Universidade Federal do Rio Grande do Sul, Porto Alegre. 